\title{
KARAKTERITIK PASIEN TERKAIT KECEMASAN DALAM MENJALANI PROSEDUR KOLONOSKOPI
}

\section{Patient Characteristics Related to Anxiety in Undergoing Colonoscopy Procedure}

\author{
Ratri Ismiwiranti1, Nursalam2, Erna Dwi Wahyuni2
}

1. Mahasiswa Magister Ilmu Keperawatan Fakultas Keperawatan Universitas Airlangga Surabaya

2. Dosen Magister Ilmu Keperawatan Fakultas Keperawatan Universitas Airlangga Surabaya

\section{Riwayat artikel}

Diajukan: 5 Agustus 2019

Diterima: 28 Maret 2020

\section{Penulis Korespondensi:}

- Ratri Ismiwiranti

- Universitas Airlangga

Surabaya

ratri290386@gmail.com

\section{Kata Kunci:}

Kecemasan, Kolonoskopi, Penelitian Kualitatif

\begin{abstract}
Abstrak
Pendahuluan: Pasien yang menjalani prosedur kolonoskopi seringkali mengalami kecemasan. Perawat perlu mengetahui penyebab dan memberikan intervensi secara khusus untuk meningkatkan keberhasilan tindakan. Tujuan penelitian ini adalah mendeskripsikan karakteristik pasien yang menjalani kolonoskopi terkait kecemasan yang dirasakan. Metode: Desain penelitian ini adalah deskriptif kualitatif dengan pendekatan studi kasus. Lokasi penelitian di Unit Endoskopi RSUD dr Abdoer Rahem Situbondo dan RSD dr. Koesnadi Bondowoso, Jawa Timur. Rekruitmen partisipan dilakukan dengan purposive sampling sampai mencapai saturasi. Responden dalam penelitian ini berjumlah 9 partisipan. Wawancara mendalam dilakukan dengan menggunakan pedoman wawancara semi-struktur dan dilakukan perekaman. Analisis data secara deskriptif. Hasil: karakteritik 9 pasien yang menjalani kolonoskopi dapat dilihat dari usia, jenis kelamin, pekerjaan, indikasi, diagnosa awal, frekuensi dan kesiapannya. Hanya 3 orang pasien yang menyatakan siap dan mampu mengontrol kecemasan yang dirasakan. Karakteristik pasien tidak terkait secara langsung dengan kecemasan yang dirasakan. Diskusi: Kecemasan yang dirasakan oleh pasien tidak hanya terkait karakteritik pasien melainkan lebih dipengaruhi faktor psikologis, persepsi, dan harapan pasien terhadap tindakan kolonskopi, oleh karena itu perlu diberikan intervensi khusus untuk mengontrol kecemasan yang dialami sehingga tujuan pemeriksaan dapat tercapai dengan optimal.
\end{abstract}

\section{Abstract}

Introduction: Patients undergoing colonoscopy procedures often experience anxiety. Nurses need to know the cause and give intervention specifically to improve the success of the action. The purpose of this research is to describe the characteristics of patients undergoing the perceived anxiety-related colonoscopy. Methods: The design of this research is a qualitative descriptive with a case study approach. Location of research in endoscopy Unit of RSUD Dr Abdoer Rahem Situbondo and RSD Dr. Koesnadi Bondowoso, East Java. Participants' recruitments are carried out purposive sampling until they reach saturation. Respondents in this study amounted to 9 participants. Indepth interviews were conducted using semi-structural interviews and performed recordings. Descriptive data analysis. Result: Characterizing 9 patients undergoing colonoscopy can be seen from age, gender, occupation, indications, preliminary diagnosis, frequency and readiness. Only 3 patients are said to be ready and able to control the perceived anxiety. Characteristics of patients not directly related to the perceived anxiety. Discussion: The anxiety felt by the patient not only related to the charactertic of the patient but rather more influenced by the psychological factors, perception, and patient's expectation of colonscopic action, therefore it is necessary to give special intervention to control The purpose of the examination can be achieved optimally. 
Jurnal Ilmiah Keperawatan (Scientific Journal of Nursing), Vol 6, No 1, Tahun 2020

(Ismiwiranti, R, et al, 2020) 


\section{PENDAHULUAN}

Kolonoskopi merupakan pemeriksaan untuk mengetahui kelainan pada saluran cerna bagian bawah yang efektif. Pemeriksaan kolonoskopi dilakukan dengan menggunakan scope untuk mengetahui kelainan mulai dari rectum, usus besar, sampai dengan sekum, kelainan yang paling sering ditemui adalah adanya kanker usus, polip yang merupakan pra kanker, perdarahan, infeksi, hemmoroid. Kolonoskopi merupakan salah satu teknik pemeriksaan yang lebih unggul dibandingkan yang lain karena dapat mengetahui gambaran usus secara jelas (Mclachlan, Clements, \& Austoker, 2012).

Pasien yang akan menjalani kolonokopi seringkali melaporkan hambatan yang dirasakannya. Kecemasan menjadi hal yang sangat mempengaruhi kesiapan pasien dalam menjalani prosedur. Kecemasan yang dialami pasien terkait dengan persiapan, prosedur, lingkungan dann hasil (Boustani, Pakseresht, Haghdoust, Qanbari, \& Mehregan-nasab, 2017; Xiaolian, Xiaolin, \& Lan, 2015). Kecemasan menjadi hambatan yang paling sering dilaporkan oleh pasien, berdasarkan hasil systematic review terdahulu disebabkan karena: 1) Ketakutan akan sensasi yang tidak menyenangkan selama kolonoskopi, 2) ketakutan akan hasil yang buruk dari pemeriksaan yang dilakukan, 3) kurangnya informasi yang adekuat tentang kolonoskopi, 4) merasa asing dengan lingkungan rumah sakit, 5) ketakutan akan efek samping kolonoskopi (Mclachlan et al., 2012).

Penelitian terdahulu menunjukkan $52 \%$ responden wanita dengan rata-rata usia 56 tahun (dari 1314 responden) menunjukkan angka kecemasan $>70$ (kecemasan tinggi), dilihat dari 3 indikator yaitu 18\% disebabkan karena bowel preparation, 29\% terkait prosedur, dan $28 \%$ berhubungan dengan procedure result. Tingginya kecemasan terkait bowel preparation dipengaruhi oleh jenis kelamin wanita, instruksi yang kurang jelas dan menjalani tindakan pertama kali, serta persiapan yang tidak tuntas. Tingginya kecemasan terkait prosedur dipengaruhi oleh jenis kelamin yaitu wanita, pengalaman tindakan pertama kali, dan instruksi yang membingungkan. Tingginya angka kecemasan terkait hasil dipengaruhi oleh gejala yang menjadi endoskopi dan persepsi persiapan yang kurang jelas (Shafer, Walker, Waldman, Bernstein, \& Park, 2018). Penelitian tentang gambaran kecemasan pada pasien yang menjalani endoskopi di RSPAD Gatot Subroto Jakarta menunjukkan bahwa dari 38 responden yang dilkukan penilaian seluruhnya mengalami kecemasan dengan perincian $73,3 \%$ mengalami cemas ringan, $21,1 \%$ cemas sedang dan $5,3 \%$ cemas berat (Toulasik, 2013)

Identifikasi faktor yang menyebabkan kecemasan pada pasien sangat diperlukan. Namun deskripsi kecemasan yang dialami oleh pasien dilihat dari karakteristik pasien secara mendalam belum diteliti.

Perawat sebagai petugas kesehatan professional memiliki peran untuk membantu pasien dalam menyelesaikan permasalahan kesehatannya secara optimal. Perawat perlu membangun interaksi yang baik dengan pasien melalui komunikasi terapeutik yang dikombinasikan dengan intervensi keperawatan yang sesuai sehingga tujuan pemeriksaan kolonoskopi dapat tercapai dan pasien mampu beradaptasi dengan prosedur, lingkungan, petugas serta mampu menerima hasil dari pemeriksaan. Oleh karena itu peneliti tertarik untuk melakukan studi kualitatif untuk mengidentifikasi hubungan karakteritik pasien dan kecemasan yang dirasakan secara lebih mendalam.

\section{METODE}

Jenis penelitian ini adalah deskriptif kualitatif dengan pendekatan studi kasus. Research setting pada penelitian ini unit 
endoskopi RSUD dr Abdoer Rahem Situbondo dan RSU dr Koesnadi Bondowoso. Partisipan penelitian ini adalah pasien yang menjalani kolonoskopi dengan kriteria inklusi: 1) pasien dewasa (usia $>20$ tahun), 2) mampu berkomunikasi dengan bahasa Indonesia atau bahasa daerah yang dapat dipahami oleh partisipan dan peneliti, 3) kondisi hemodinamik stabil, 4) pasien tidak mendapatkan general anastesi.

Sampling dilakukan dengan purposive, partisipan berjumlah 9 orang. Instrument HASIL

Penelitian dilakukan pada 12 Maret 2019 - 24 Juni 2019 di Unit Endoskopi RSUD dr Abdoer Rahem Situbondo dan RSU dr Koesnadi Bondowoso. Partisipan mencapai saturasi sebanyak 17 orang dengan karakteristik sebagai berikut:

\section{Gambaran karakteristik responden}

Tabel 1 Karakteristik Responden

\begin{tabular}{|c|c|c|c|c|c|c|c|c|c|}
\hline $\mathbf{P}$ & Usia & $\begin{array}{l}\text { Jenis } \\
\text { kelamin }\end{array}$ & Status & Pendidikan & Pekerjaan & Dx Awal & Indikasi & frek & Kesiapan \\
\hline 1 & 54 & $\mathrm{P}$ & Menikah & $\mathrm{TS}$ & Buruh & $\begin{array}{l}\text { Susp } \\
\text { Ca colon }\end{array}$ & $\begin{array}{l}\text { Nyeri perut, } \\
\mathrm{CBH}\end{array}$ & 1 & Tidak \\
\hline 2 & 51 & $\mathrm{P}$ & Menikah & SD & IRT & $\begin{array}{l}\text { Susp } \\
\text { Ca colon }\end{array}$ & $\begin{array}{l}\text { Nyeri perut, } \\
\text { benjolan }\end{array}$ & 3 & $\mathrm{Ya}$ \\
\hline 3 & 44 & $\mathrm{~L}$ & Menikah & SD & Petani & $\begin{array}{l}\text { Susp } \\
\text { Ca colon }\end{array}$ & $\mathrm{CBH}$ & 1 & Tidak \\
\hline 4 & 41 & $\mathrm{P}$ & Menikah & $\mathrm{S} 1$ & IRT & $\begin{array}{l}\text { Post } \\
\text { colostomy }\end{array}$ & $\mathrm{CBH}$ & 1 & Tidak \\
\hline 5 & 43 & $\mathrm{P}$ & Menikah & SMA & Wiraswasta & $\mathrm{CBH}$ & Diare kronis & 1 & Tidak \\
\hline 6 & 78 & $\mathrm{~L}$ & Menikah & SMA & Swasta & Susp Ca Colon & Nyeri perut & 4 & $\mathrm{Ya}$ \\
\hline 7 & 38 & $\mathrm{P}$ & Menikah & SMA & IRT & $\begin{array}{l}\text { Susp colitis } \\
\text { kronis }\end{array}$ & $\begin{array}{l}\text { Nyeri perut } \\
\text { Diare ada } \\
\text { darah }\end{array}$ & 1 & Tidak \\
\hline 8 & 55 & $\mathrm{P}$ & Menikah & TTS & Wiraswasta & Hematochezia & $\begin{array}{l}\text { Nyeri perut, } \\
\text { BAB ada } \\
\text { darah }\end{array}$ & 1 & $\mathrm{Ya}$ \\
\hline 9 & 63 & $\mathrm{P}$ & Menikah & S1 & Pensiunan & Colitis & Nyeri perut & 2 & Tidak \\
\hline
\end{tabular}

*TS: Tidak Sekolah

*TTS: Tidak Tamat SD

*CBH: Change Bowel Habit yang digunakan selain peneliti sendiri ditunjang dengan pedoman wawancara mendalam (in-depth interview), catatan Penelitian dilakukan selama 5 minggu. Data dianalisis dengan menggunakan metode colaizzi.

Persetujuan etik dikeluarkan oleh Komite Etik Penelitian Kesehatan (KEPK) Fakultas Keperawatan Universitas Airlangga dengan Nomor: 1306-KEPK . lapangan (fields notes), dan alat perekam. 


\section{PEMBAHASAN}

Tindakan Endoskopi yang dilakukan pada penelitian ini adalah Endoskopi gastrointestinal pada pasien dewasa. Pemahaman pasien tentang apa dan bagaimana tindakan endoskopi sangat diperlukan (Mitchell, 2016). Pada saat persiapan endoskopi evaluasi kondisi psikologis pasien sangat diperlukan. Peningkatan pemahaman pasien, kepatuhan dan kesiapa juga perlu diperlukan untuk mengurangi biaya (efektif dan efisien) (Abuksis et al., 2001). Kemapuan pasien untuk beradaptasi dengan kecemasna yang dirasakan akibat pemeriksaan adalah respon subjektif dari banyak faktor yang dipengaruhi oleh pasien. Usia peserta pada penelitian ini sebagian besar berusia 51-58 tahun $(\mathrm{n}=3)$, hal ini sejalan dengan penelitian sebelumnya (Izanloo et al., 2015). Kondisi ini menunjukkan bahwa kesiapan pasien didukung oleh kondisi mental dan emosional pasien dalam rentang usia lebih matang. Jenis kelamin peserta yang siap untuk menjadi perempuan $(n=4)$, ini bertentangan dengan penelitian sebelumnya (Behrouzian, Sadrizadeh, Nematpour, \& Seyedian, 2017; Boustani et al., 2017), hasil ini dipengaruhi oleh budaya bahwa perempuan dianggap lebih kuat dalam menghadapi masalah dan sering menghadapi banyak tugas. Status perkawinan peserta sudah menikah, hal ini sejalan dengan penelitian sebelumnya (Boustani et al., 2017), dukungan emosional orang sekitar membantu pasien untuk lebih siap untuk prosedur. Pendidikan partsipan antara sekolah dasar dan SMA, ini bertentangan dengan penelitian sebelumnya (Hsueh et al., 2016), latar belakang pendidikan mempengaruhi pemahaman pasien tentang informasi yang diberikan. Indikasi tindakan yang paling banyak adalah sakit perut $(n=4)$, hal ini sejalan dengan penelitian sebelumnya. Peserta memiliki pengalaman endoskopi sebelumnya $(\mathrm{n}=3)$, hal ini sejalan dengan penelitian sebelumnya (Shafer et al., 2018), pengalaman sebelumnya memberikan gambaran prosedur endoskopi sehingga pasien lebih siap dan mampu mengontrol kecemasan yang dirasakan. Jenis tindakan yang dilakukan oleh kolonoskopi $(\mathrm{n}=9)$ dan EGD $(\mathrm{n}=8)$, pasien mengekspresikan kesiapannya mengenai tindakan lebih berfokus pada manfaat yang diperoleh dari prosedur yang dilakukan dan memiliki kontrol perilaku yang baik untuk beradaptasi dengan hal yang kurang menyenangkan.

Latar belakang karakteristik pasien sedikit mempengaruhi kemampuan pasien untuk mengelola kecemasan yang dirasakan. Bayangan yang kurang menyenangkan terkait hasil merupakan hal yang mempengaruhi kemampuan pasien untuk beradaptasi (Pontone et al., 2015). Perawat Endoskopi sebagai pemberi asuhan memiliki tanggung jawab untuk mempersiapkan pasien, mendampingi, sampai dengan evaluasi pasca-tindakan (Beilenhoff, President, Society, Dip, \& Past, 2011).

Komunikasi menjadi kunci utama keberhasilan dalam penyampaian informasi. Perawat perlu memberikan informasi yang lengkap dan jelas yang berkaitan dengan tindakan endoskopi termasuk hal yang kurang menyenangkan (Arabul et al., 2013; Gallaher \& Parisinos, 2015) dan juga bagaimana pasien dapat beradaptasi dengan kondisi ini, termasuk kemungkinan terjadi. Perawat perlu memberikan intervensi kepada pasien seperti hipnosis, audio, video, yoga, aromaterapi yang dapat meningkatkan kepatuhan, kesiapan, dan mengurangi kecemasan. Intervensi ini dapat meningkatkan pemahaman pasien tentang tindakan, persepsi positif dan peningkatan perilaku adaptif untuk menurunkan ketidaknyamanan yang dirasakan ((Izanloo et al., 2015)(Hozumi et al., 2017)(Leung, 2008)(Drouet \& Chedeau, 2017)(Boselli, Musellec, Martin, Bernard, \& Fusco, 2017)(Li, Shu, Li, \& Liu, 2019)(Domínguez-ortega \& Rodríguezmuñoz, 2010)

\section{KESIMPULAN DAN SARAN}




\section{Kesimpulan}

Penelitian ini memperkuat penelitian terdahulu yang menunjukkan bahwa kecemasan yang dirasakan pasien yang menjalani kolonoskopi beragam. Pengalaman terdahulu memang membantu pasien untuk lebih mudah dalam mengelola kecemasan yang dialaminya namun pada penelitian ini ditemukan juga pasien yang mampu mengelalola kecemasannya walaupun baru pertama kami menjalani tindakan.

Kesiapan pasien secara psikologis adalah faktor yang sangat mempengaruhi kemampuannya dalam mengelola kecemasan yang dialami. Persepsi yang positif dengan melihat manfaat dari kolonoskopi membuat pasien mengesampingkan hal yang kurang menyenangkan terkait tindakan.

Di lain sisi dukungan tetap diperlukan untuk memperkuat psikologis pasien namun karakteristik pasien tidak terkait secara langsung dengan kecemasan yang dirasakan.

\section{Saran}

Perawat dapat menggunakan hasil identifikasi untuk menentukan intervensi yang tepat dalam menurukan kecemasan yang dialami oleh pasien kolonoskopi.

\section{DAFTAR PUSTAKA}

Abuksis, G., Sc, M., Mor, M., Segal, N., Sc, I. S. B., Morad, I., ... Plaut, S. (2001). A Patient Education Program Is CostEffective for Preventing Failure of Endoscopic Procedures in a Gastroenterology Department, 96(6). Arabul, M., Kandemir, A., Celik, M., Torun, S., Beyazit, Y., Alper, E., \& Camci, M. (2013). Impact of video information before unsedated upper gastrointestinal endoscopy on patient satisfaction and anxiety : a prospective randomized trial, 8(1). https://doi.org/10.5114/pg.2013.3418 2

Behrouzian, F., Sadrizadeh, N., Nematpour, S., \& Seyedian, S. S. (2017). The Effect of Psychological Preparation on the Level of Anxiety before Upper Gastrointestinal Endoscopy. https://doi.org/10.7860/JCDR/2017/2 4876.10270

Beilenhoff, U., President, E. P., Society, G., Dip, N., \& Past, E. (2011). Best Practice \& Research Clinical Gastroenterology Quality assurance in endoscopy nursing. Best Practice \& Research Clinical Gastroenterology, 25(3), 371-385. https://doi.org/10.1016/j.bpg.2011.05. 005

Boselli, E., Musellec, H., Martin, L., Bernard, F., \& Fusco, N. (2017). Effects of hypnosis on the relative parasympathetic tone assessed by ANI ( Analgesia / Nociception Index ) in healthy volunteers: a prospective observational study. Journal of Clinical Monitoring and Computing, $O(0)$, https://doi.org/10.1007/s10877-0170056-5

Boustani, H., Pakseresht, S., Haghdoust, M., Qanbari, S., \& Mehregan-nasab, H. (2017). Effect of psychological preparation on anxiety level before colo- noscopy in outpatients referred to Golestan Hospital in Ahvaz, 12(3), 235-239.

https://doi.org/10.1007/s11515-0171451-5

Domínguez-ortega, L., \& Rodríguezmuñoz, S. (2010). American Journal of Clinical The Effectiveness of Clinical Hypnosis in the Digestive Endoscopy : A Multiple Case Report, (January 2015), 37-41. https://doi.org/10.1080/00029157.201 0.10404332

Drouet, N., \& Chedeau, G. (2017). Journal of Clinical Anesthesia Hypnopraxia , a new hypnotic technique for hypnoanesthesia is. Journal of Clinical Anesthesia, 37, 14-16. https://doi.org/10.1016/j.jclinane.201 6.10 .039

Gallaher, A. J., \& Parisinos, C. (2015). Endoscopy patient satisfaction 
survey: improving the patient experience, 2(2), 2015.

Hozumi, H., Hasegawa, S., Tsunenari, T., Sanpei, N., Arashina, Y., Takahashi, K., ... Tomimatsu, S. (2017). Complementary Therapies in Medicine Aromatherapies using Osmanthus fragrans oil and grapefruit oil are e ff ective complementary treatments for anxious patients undergoing colonoscopy: A randomized controlled study. Complementary Therapies in Medicine, 34(August), 165-169. https://doi.org/10.1016/j.ctim.2017.08 .012

Hsueh, F., Chen, C., Sun, C., Chou, Y., Hsiao, S., \& Yang, T. (2016). A Study on the Effects of a Health Education Intervention on Anxiety and Pain During Colonoscopy Procedures, 24(2), 181-189. https://doi.org/10.1097/jnr.000000000 0000112

Izanloo, A., Fathi, M., Izanloo, S., Vosooghinia, H., Hashemian, A., Sadrzadeh, S. M., \& Ghaffarzadehgan, K. (2015). Efficacy of Conversational Hypnosis and Propofol in Reducing Adverse Effects of Endoscopy, 5(5). https://doi.org/10.5812/aapm.27695

Leung, F. W. (2008). Methods of Reducing Discomfort During Colonoscopy, 1462-1467.

https://doi.org/10.1007/s10620-0070025-9

Li, L., Shu, W., Li, Z., \& Liu, Q. (2019). Pain Management Nursing Using Yoga Nidra Recordings for Pain Management in Patients Undergoing Colonoscopy. Pain Management Nursing, 20(1), 39-46. https://doi.org/10.1016/j.pmn.2018.04 .005

Mclachlan, S., Clements, A., \& Austoker, J. (2012). Patient Education and Counseling Patients' experiences and reported barriers to colonoscopy in the screening context - A systematic review of the literature, 86, 137-146. https://doi.org/10.1016/j.pec.2011.04. 010

Mitchell, M. (2016). Day surgery nurses ' selection of patient preoperative information, 1-13. https://doi.org/10.1111/jocn.13375

Pontone, S., Tonda, M., Brighi, M., Florio, M., Pironi, D., \& Pontone, P. (2015). Does Anxiety or Waiting Time Influence Patients , Tolerance of Upper Endoscopy?, 21(2), 111-116. https://doi.org/10.4103/13193767.153839

Shafer, L. A., Walker, J. R., Waldman, C., Bernstein, C. Y. V. M. C. N., \& Park, L. H. J. (2018). Factors Associated with Anxiety About Colonoscopy: The Preparation, the Procedure, and the Anticipated Findings. Digestive Diseases and Sciences, (0123456789). https://doi.org/10.1007/s10620-0184912-z

Toulasik, A. (2013). Gambaran Tingkat Kecemasan Pasien yang Akan Menjalani Prosedur Endoskopi Saluran Cerna di Rumah Sakit Pusat Angkatan Darat Gatot Soebroto Jakarta.

Xiaolian, J., Xiaolin, L., \& Lan, Z. H. (2015). Effects of Visual and Audiovisual Distraction on Pain and Anxiety Among Patients Undergoing Colonoscopy, 38(1), 55-61. https://doi.org/10.1097/SGA.0000000 000000089 